\title{
Counting, analysing and reporting exacerbations of COPD in randomised controlled trials
}

\author{
S D Aaron, ${ }^{1}$ D Fergusson, ${ }^{1}$ G B Marks, ${ }^{2}$ S Suissa, ${ }^{4} \mathrm{~K}$ L Vandemheen, ${ }^{1}$ S Doucette, ${ }^{1}$ \\ F Maltais, ${ }^{3} \mathrm{~J}$ F Bourbeau, ${ }^{4} \mathrm{R}$ S Goldstein, ${ }^{5} \mathrm{M}$ Balter, ${ }^{5} \mathrm{D}$ O'Donnell, ${ }^{6} \mathrm{M}$ FitzGerald, \\ for the Canadian Thoracic Society/Canadian Respiratory Clinical Research Consortium
}

\begin{abstract}
- Additional data are published in the online Appendix at http:// thorax.bmj.com/content/vol63/ issue2
\end{abstract}

\section{${ }^{1}$ The Ottawa Health Research Institute, University of Ottawa, Ottawa, Canada; ${ }^{2}$ The Woolcock Institute of Medical Research, Sydney, Australia; \\ ${ }^{3}$ Centre de recherche, Hopital Laval, Universite Laval, Montreal, Canada; ${ }^{4}$ Department of Medicine, McGill University, Montreal, Canada: ${ }^{5}$ Department of Medicine, The University of Toronto, Toronto, Canada; ${ }^{6}$ The Department of Medicine, Queen's University, Canada; \\ ${ }^{7}$ Department of Medicine, The University of British Columbia, Canada}

Correspondence to: Dr S D Aaron, The Ottawa Hospital, General Campus, 501 Smyth Road, Ottawa, Ontario, Canada, K1H 8L6; saaron@ohri. ca

Received 10 April 2007 Accepted 12 July 2007

Published Online First

16 August 2007

\section{ABSTRACT}

Background: Clinical trials measure exacerbations of chronic obstructive pulmonary disease (COPD) inconsistently. A study was undertaken to determine if different methods for ascertaining and analysing COPD exacerbations lead to biased estimates of treatment effects.

Methods: Information on the methods used to count, analyse and report COPD exacerbation rates was abstracted from clinical trials of long-acting bronchodilators or long-acting bronchodilator/inhaled steroid combination products published between 2000 and 2006. Data from the Canadian Optimal Therapy of COPD Trial was used to illustrate how different analytical approaches can affect the estimate of exacerbation rates and their confidence intervals.

Results: 22 trials (17 156 patients) met the inclusion criteria and were reviewed. None of the trials adjudicated exacerbations or determined independence of events. 14/22 studies (64\%) introduced selection bias by not analysing outcome data for subjects who prematurely stopped study medications. Only $31 \%$ of trials used timeweighted analyses to calculate the mean number of exacerbations/patient-year and only 15\% accounted for between-subject variation. In the Canadian Optimal Therapy of COPD Trial the rate ratio for exacerbations/ patient-year was 0.85 when all data were included in a time-weighted analysis, but was overestimated as 0.79 when data for those who prematurely stopped study medications were excluded and was further overestimated as 0.46 when a time-weighted analysis was not conducted; $p$ values ranged from 0.03 to 0.24 depending on how exacerbations were determined and analysed.

Conclusions: Clinical trials have used widely different methods to define and analyse COPD exacerbations and this can lead to biased estimates of treatment effects. Future trials should strive to include blinded adjudication and assessment of the independence of exacerbation events, and trials should report time-weighted intentionto-treat analyses with adjustments for between-subject variation in COPD exacerbations.

Patients with chronic obstructive pulmonary disease (COPD) exhibit slow progressive deterioration in airflow and respiratory status that can be punctuated by acute episodes of clinical deterioration known as COPD exacerbations. Acute exacerbations of COPD are characterised clinically by acute or subacute worsening of respiratory symptoms and may include abrupt increases in cough, sputum production, sputum purulence and breathlessness.

COPD exacerbations have an important negative impact on health-related quality of $\operatorname{life}^{2-4}$ and generate considerable economic costs. ${ }^{5}$ The prevention of exacerbations is now recognised as a primary goal of COPD therapy. ${ }^{6}$ Earlier trials of COPD therapy considered lung function as the primary outcome and analysed exacerbations as secondary outcomes. ${ }^{78}$ More recently, many clinical trials of maintenance medications for COPD have evaluated COPD exacerbation rates as a primary outcome. Unfortunately, clinical trials have not been consistent in how they count, record or analyse COPD exacerbation rates, and methodological errors in the assessment of COPD exacerbations may lead to biased or spurious results.

The objective of this study was twofold. The first objective was to perform a systematic review of clinical trials published since 2000 to document potential inconsistencies in how COPD exacerbations were counted, analysed and reported among published studies. The second objective was to use data from a clinical trial to illustrate how differences in methodology and analysis affect the accuracy and precision of the results, and to determine if improper methods for ascertaining and analysing COPD exacerbation rates lead to biased estimates of treatment effects. It is hoped that this study will provide valuable information to help investigators design future intervention studies that evaluate acute exacerbations of COPD.

\section{METHODS}

We performed a systematic literature search of the MEDLINE and Cochrane Clinical Trials Registry Databases to identify randomised controlled trials, published in print or on the internet between 2000 and November 2006, of patients with COPD who were treated with long-acting $\beta$ agonist bronchodilators, long-acting anticholinergic bronchodilators or long-acting $\beta$ agonist/inhaled corticosteroid combination products. Studies published in any language were included if they were randomised controlled trials that reported COPD exacerbation rates as a primary or secondary outcome. The search was performed using the search terms: COPD, chronic obstructive pulmonary disease, or obstructive airway disease; and adrenergic $\beta$ agonist, long-acting $\beta$-agonists, administration/ inhalation, formoterol, salmeterol, anticholinergic, cholinergic antagonist, tiotropium, inhaled corticosteroid, fluticasone-salmeterol, salmeterol-fluticasone, budesonide-formoterol or formoterolbudesonide. In addition, relevant systematic reviews and meta-analyses were reviewed and all references of identified trials were retrieved. 
Information on the methods used in each study was extracted to define, count, record and analyse acute exacerbations of COPD. Specific issues assessed were:

- Counting exacerbation events

- Analysing exacerbation events

- Reporting exacerbation events

\section{Counting exacerbation events}

- Was the definition of an acute exacerbation of COPD used a symptom-based or event-based definition? A symptombased definition uses a complex of worsening respiratory symptoms to define an acute exacerbation of COPD whereas an event-based definition requires a therapeutic intervention such as a change in COPD medications or a change in healthcare utilisation to define an event. ${ }^{6}$

- How did investigators distinguish between new exacerbations and slow-to-resolve exacerbations or relapse of previous exacerbations? Was independence of individual events assured?

- Was there blinded adjudication of exacerbation events to ensure consistency with the study definition?

- Were patients maintained in the study regardless of whether they prematurely discontinued study treatments?

\section{Analysing exacerbation events}

Patients may drop out early from clinical trials. An unweighted statistical approach does not adjust for time spent in the trial, and it therefore produces a biased estimate because it overestimates exacerbations that occur in patients who drop out early. In contrast, a weighted statistical approach adjusts for asymmetry in follow-up times by accounting for each patient's time spent in the trial, and this approach produces an unbiased estimate. ${ }^{9}$ A second issue is that, in most parallel group clinical trials, variations between subjects in the effect of treatment results in overdispersion of residuals in a standard parametric analysis. This leads to inappropriate narrowing of the confidence intervals around the estimate. This can be corrected either by using a Poisson distribution with adjustment for the estimated overdispersion parameter or by using a negative binomial error distribution. ${ }^{9} 10$

We therefore assessed:

- Was a weighted statistical approach used to account for duration of patient follow-up? ${ }^{9} 10$

- Were recommended statistical techniques used to account for variability in exacerbation rates between patients? ${ }^{9} 10$

\section{Reporting exacerbation events}

- Did studies report the proportion of subjects who experienced an exacerbation in addition to the mean exacerbation events/patient-year?

Finally, data from the Canadian Optimal Therapy of COPD Trial $^{11}$ were analysed to determine how the rate of exacerbations/patient-year and the resultant rate ratio were affected by:

- Use of blinded adjudication and assessment of independence of exacerbation events.

- Exclusion of patients when they prematurely discontinued study medications.

- Use of time-weighted compared with unweighted mean rates.

- Use of overdispersion corrections to assess the statistical significance of the results.

\section{RESULTS}

Results of the systematic review

A total of 339 potentially relevant citations were retrieved, from which 35 published clinical trials were identified which potentially fulfilled the inclusion criteria. Of these, 13 articles were excluded ( 9 because exacerbations were only identified as adverse events and were not identified as a primary or secondary outcome $e^{12-2024}$ and 3 because the results overlapped with previously published trials ${ }^{21-23}$ ).

Of the 22 trials included, 7 evaluated long-acting $\beta$ agonists (LABAs), ${ }^{25-31} 8$ studied LABA/inhaled steroid combination products (all of these studies also included a LABA arm), ${ }^{32-39}$ and 7 studies evaluated a long-acting anticholinergic bronchodilator ( 2 of these studies also included a LABA arm).$^{40-46}$ The characterstics of the 22 trials included in the systematic review are shown in the table in the online Appendix.

\section{Definition of COPD exacerbation used}

Seventeen of the 22 studies (77\%) used an event-based definition of COPD exacerbations (see online table). Of the 17 studies, 11 limited their definition to exacerbation episodes that required new treatment with antibiotics and/or systemic corticosteroids and/or hospitalisation to count as an eventbased outcome. Six studies (27\%) also counted "mild exacerbations", defined as days requiring increased use of as-needed inhalations of reliever medication above the usual daily use.

Four of the 22 studies (18\%) used a symptom-based definition of acute exacerbations of COPD, defined as a complex of worsening respiratory symptoms lasting at least 3 days which was not necessarily associated with a therapeutic intervention. One study used a symptom-based definition to identify mild exacerbations and an event-based definition to identify moderate or severe exacerbations. ${ }^{29}$

\section{Methods used to count exacerbations and enhance the quality of exacerbation measurements}

Independence of events

None of the 22 trials reported whether they determined independence of individual exacerbation events, and none reported whether they used criteria to distinguish a new exacerbation event from a relapse of the original exacerbation. One study did state criteria for how they determined the end point of a mild exacerbation, but did not state equivalent criteria by which they determined the end point of a moderate or severe exacerbation. ${ }^{38}$

\section{Adjudication of exacerbation events}

None of the 22 trials reported whether they obtained medical records from the patient or healthcare provider in order to adjudicate suspected exacerbation events. None of the studies described quality control measures to ensure that events counted as exacerbations were consistent with the study definition of exacerbation.

\section{Premature withdrawal of patients}

Only one study explicitly stated that attempts were made to follow all patients for the full duration of the study and record all exacerbation events, regardless of whether patients continued on study medications. ${ }^{43}$ Fourteen of the 22 studies (64\%) automatically withdrew patients from the study if they stopped study drugs and these studies did not continue to monitor these patients or record any subsequent exacerbation events. 
Table 1 Description of the Canadian Optimal Therapy of COPD Trial exacerbation results: adjudicated exacerbations

\begin{tabular}{lll}
\hline $\begin{array}{l}\text { No of exacerbations } \\
\text { during the 1-year study }\end{array}$ & $\begin{array}{l}\text { Tiotropium + placebo } \\
\text { (N= 156 patients) }\end{array}$ & $\begin{array}{l}\text { Tiotropium + fluticasone/ } \\
\text { salmeterol } \\
\text { (N= 145 patients) }\end{array}$ \\
\hline 0 & $37.2 \%$ & $40.0 \%$ \\
1 & $28.8 \%$ & $23.4 \%$ \\
2 & $13.5 \%$ & $17.9 \%$ \\
3 & $9.6 \%$ & $10.3 \%$ \\
4 & $2.6 \%$ & $3.4 \%$ \\
5 & $4.5 \%$ & $3.4 \%$ \\
6 & $2.6 \%$ & $1.4 \%$ \\
7 & $0.6 \%$ & $0.0 \%$ \\
8 & $0.6 \%$ & $0.0 \%$ \\
Total no of adjudicated & 222 & 188 \\
exacerbations & & \\
Range & $0-8$ & $0-6$ \\
Total person-years of follow-up & 138.0 & 137.0 \\
Weighted mean adjudicated & 1.61 & 1.37 \\
exacerbation rate per patient-year & \\
\hline
\end{tabular}

\section{Methods used to analyse exacerbation rates statistically}

Of the13 trials that reported the mean number of exacerbations/patient-year, only 4 (31\%) used analyses which weighed each patient's individual exacerbation rate by their follow-up time. $^{33-3539}$ Of the 13 trials that reported the mean number of exacerbations/patient-year, only $2(15 \%)$ accounted for the effect of between-subject variation on precision of the estimates by incorporating an overdispersion parameter in the analysis. ${ }^{33} 35$

\section{Methods used to report exacerbation rates}

Nine of the 22 trials reported the proportion of patients experiencing an exacerbation in each treatment group, 7 reported the mean number of exacerbations/patient-year and 6 reported both the proportions experiencing an exacerbation and the mean number of exacerbations/patient-year.

\section{Effects of alternative methods for counting and analysing acute exacerbations of COPD on a real clinical trial data set}

Data from the Canadian Optimal Therapy of COPD Trial were analysed to determine how the rate of exacerbations per patient per year and the resultant rate ratio and confidence intervals were affected by alternative methods of counting and analysing COPD exacerbations.

The Optimal Trial randomised 449 patients with moderate or severe COPD to 1 year of treatment with tiotropium + placebo or tiotropium + salmeterol or tiotropium + fluticasone/ salmeterol. ${ }^{11}$ The primary outcome was the proportion of patients in each treatment group who experienced a COPD exacerbation requiring treatment with oral or intravenous steroids and/or antibiotics within 52 weeks of randomisation. Patients were followed for the full 52-week duration of the trial and primary and secondary outcomes were recorded throughout the 1-year period regardless of whether patients had experienced an exacerbation or discontinued study medications. A patient was considered to have experienced a new COPD exacerbation if they had been off oral steroids and antibiotics for at least 14 days following their previous exacerbation. For every suspected exacerbation a full report was prepared which included a patient symptom questionnaire as well as physician, emergency department and hospital records describing the circumstances of each suspected exacerbation. The assembled data from the suspected exacerbation visit was presented to a
Table 2 Comparison of non-adjudicated event rates (without assurance of independence of exacerbation events) with adjudicated exacerbation rates in the Canadian Optimal Therapy of COPD Trial

\begin{tabular}{|c|c|c|}
\hline & $\begin{array}{l}\text { Tiotropium + placebo } \\
\text { ( } \mathrm{N}=156 \text { patients) }\end{array}$ & $\begin{array}{l}\text { Tiotropium + fluticasone/ } \\
\text { salmeterol } \\
\text { ( } N=145 \text { patients) }\end{array}$ \\
\hline Total follow-up time & 138 person-years & 137 person-years \\
\hline $\begin{array}{l}\text { Total number of non- } \\
\text { adjudicated events }\end{array}$ & 288 & 250 \\
\hline $\begin{array}{l}\text { Total number of adjudicated } \\
\text { COPD exacerbations }\end{array}$ & 222 & 188 \\
\hline $\begin{array}{l}\text { Weighted mean rate of non- } \\
\text { adjudicated events/patient- } \\
\text { year }\end{array}$ & 2.09 & 1.82 \\
\hline $\begin{array}{l}\text { Weighted mean rate of } \\
\text { adjudicated exacerbations/ } \\
\text { patient-year }\end{array}$ & 1.61 & 1.37 \\
\hline
\end{tabular}

blinded Adjudication Committee which confirmed whether the event met the study definition of a COPD exacerbation, and also whether the event met the study criteria for a new exacerbation rather than a relapse or continuation of a previously recorded exacerbation.

Although the Optimal Trial had three treatment arms, for the purposes of illustration only two treatment arms (tiotropium + placebo and tiotropium + fluticasone/salmeterol) are presented (table 1). Patients randomised to receive tiotropium + placebo experienced 222 exacerbations/138 patient-years of followup $=1.61$ exacerbations/patient-year compared with 188 exacerbations $/ 137$ patient-years of follow-up $=1.37$ exacerbations/patient-year in those randomised to receive tiotropium + fluticasone/salmeterol. The weighted rate ratio is simply calculated as $1.37 / 1.61=0.85$, and the relative risk reduction is therefore equal to $15 \%$.

Table 2 shows the effects of failure to determine the independence and validity of reported possible exacerbation events through adjudication. The Optimal Trial considered patients to have experienced a new COPD exacerbation if they had been off oral steroids and antibiotics for at least 14 days following their previous exacerbation; 66/288 possible exacerbation events (23\%) in the tiotropium + placebo group and 62/ 250 possible events (25\%) in the tiotropium + fluticasone/ salmeterol group were adjudicated and judged not to be true exacerbation events, either because they did not meet the study definition of exacerbation (eg, patient received antibiotics for sinusitis rather then COPD exacerbation) or because they were not independent events (eg, patient presented for COPD exacerbation on two occasions within 1 week). If these suspected events had not been excluded by adjudication, this would have artificially inflated the rate of exacerbations in each treatment group producing a small change in the rate ratio (table 3).

Table 3 shows the effects of using an unweighted mean approach to determine rates of exacerbation. This approach divides each patient's number of exacerbations by the length of time each patient was followed. The mean rate for the group is then estimated using the average of these individual patient rates. In contrast, a weighted approach divides the total number of exacerbations in a treatment group by the total duration of follow-up time of the group. As shown in table 4, use of an unweighted approach produces a biased estimate of the mean rates and consequently the rate ratio, since individuals who drop out of a study early after having had one or more exacerbations will contribute proportionally more to the mean rate than if they were analysed using unbiased time-weighted 
Table 3 Mean exacerbation rate per patient-year in the Canadian Optimal Therapy of COPD Trial

\begin{tabular}{|c|c|c|c|}
\hline & $\begin{array}{l}\text { Tiotropium + placebo } \\
\text { ( } \mathrm{N}=156 \text { patients) }\end{array}$ & $\begin{array}{l}\text { Tiotropium + fluticasone/ } \\
\text { salmeterol } \\
\text { ( } N=145 \text { patients) }\end{array}$ & $\begin{array}{l}\text { Rate ratio (relative } \\
\text { risk reduction) (\%) }\end{array}$ \\
\hline $\begin{array}{l}\text { Weighted mean exacerbation rate/patient-year } \\
\text { (adjudicated events) }\end{array}$ & 1.61 & 1.37 & $0.85(15)$ \\
\hline $\begin{array}{l}\text { Weighted mean exacerbation rate/patient-year } \\
\text { (non-adjudicated, independence not assured) }\end{array}$ & 2.09 & 1.82 & $0.87(13)$ \\
\hline $\begin{array}{l}\text { Weighted mean exacerbation rate/patient-year with } \\
\text { premature exclusion of patients who stop study } \\
\text { medications (adjudicated events) }\end{array}$ & 1.66 & 1.31 & $0.79(21)$ \\
\hline $\begin{array}{l}\text { Unweighted mean exacerbation rate/patient-year } \\
\text { (adjudicated events) }\end{array}$ & 2.00 & 1.48 & $0.74(26)$ \\
\hline $\begin{array}{l}\text { Unweighted mean exacerbation rate/patient-year } \\
\text { with premature exclusion of patients who stop study } \\
\text { medications (adjudicated events) }\end{array}$ & $\begin{array}{l}4.94 \\
y^{2}+x\end{array}$ & 2.29 & $0.46(54)$ \\
\hline \multicolumn{4}{|c|}{$\begin{array}{l}\text { Row } 1 \text { shows the correct rate ratio for the trial (the maximum likelihood estimate). } \\
\text { Row } 2 \text { shows the effects of not adjudicating and assuring independence of individual exacerbation events. } \\
\text { Row } 3 \text { shows the effects of prematurely excluding patients from the trial who discontinue study medications early. } \\
\text { Row } 4 \text { shows the effects of using an unweighted statistical approach. } \\
\text { Row } 5 \text { shows the effects of both prematurely excluding patients from the trial who discontinue study medications early and of } \\
\text { using an unweighted statistical approach. }\end{array}$} \\
\hline
\end{tabular}

methods. In the dataset in the Canadian Optimal Therapy of COPD Trial, the rate ratio changes from 0.85 to 0.74 when an unweighted approach is used. This has the effect of exaggerating the benefits of treatment and inflating the relative risk reduction from $15 \%$ to $26 \%$.

Table 3 also shows the effects of excluding outcome data for patients after they prematurely stop study medications. The effect is to exaggerate the effects of treatment, such that in the Optimal dataset the rate ratio drops from 0.85 when patients are followed until termination of the one-year study period, down to 0.79 when patients are excluded at the point when they prematurely stop study medications. These effects are further compounded if an un-weighted approach is used together with premature exclusion of patients, in which case the rate ratio is even further underestimated at 0.46 . This has the effect of grossly exaggerating the benefits of treatment, and inflating the relative risk reduction from $15 \%$ to $54 \%$.

The statistical significance of the weighted rate ratios for exacerbation was assessed by the $p$ value and the precision of the estimates is presented as confidence intervals (table 4). The least biased $p$ value is produced when the intention-to-treat dataset is analysed using either a Poisson regression analysis with adjustment for overdispersion $(p=0.24)$ or a negative binomial analysis which contains a term that accounts for the degree of overdispersion $(p=0.23)$. Table 4 shows that the effect of excluding data from patients after they prematurely discontinue study medications is to narrow the confidence intervals around the estimate. Thus, $p$ values are systematically smaller and hence "more significant" when patients are prematurely excluded from the analysis. As shown in table 4, $p$ values can vary from 0.24 down to 0.03 depending on which statistical approach is used. Thus, results can easily cross the traditional threshold of statistical significance $(p=0.05)$ depending on how the data are analysed.

\section{DISCUSSION}

Our systematic review has shown that clinical trials published between 2000 and 2006 used widely varying definitions of COPD exacerbations. Even for those studies that uniformly used an event-based definition, the criteria for defining an exacerbation were highly variable. Thus, some studies included and counted "mild exacerbations" which were defined as days requiring increased use of an as-needed reliever medication, whereas others only counted exacerbations that were treated with systemic corticosteroids or antibiotics or hospitalisation. Without a consistent and standardised definition of an outcome, it is impossible to compare one trial with another-or even one medication against another-to determine the relative efficacy of different therapies in reducing the rate of COPD exacerbations.

Our review uncovered other methodological inconsistencies in how trials count and analyse COPD exacerbations. Exclusion of patients from the study analysis after they prematurely stopped study medications was common and occurred in $64 \%$ of the reviewed trials. Premature exclusion of patients may be inappropriate since it precludes an effectiveness analysis of the medication in question-ie, how the drug will act in "realworld" circumstances when some patients are non-compliant. In addition, early exclusion of patients can introduce bias because the factors which determined whether a patient might be excluded may often also be related to the outcome. For instance, some patients may prematurely discontinue a study medication because they are doing poorly and about to have an exacerbation in the near future. Premature exclusion of these

Table 4 Effect of excluding patient data after they prematurely discontinue study medications and effect of failure to correct for overdispersion

\begin{tabular}{|c|c|c|c|c|c|c|c|}
\hline \multirow[b]{2}{*}{ Trial dataset } & \multirow{2}{*}{$\begin{array}{l}\text { Weighted } \\
\text { rate ratio }\end{array}$} & \multicolumn{2}{|c|}{$\begin{array}{l}\text { Poisson analysis without } \\
\text { overdispersion correction }\end{array}$} & \multicolumn{2}{|c|}{$\begin{array}{l}\text { Poisson analysis with } \\
\text { overdispersion correction }\end{array}$} & \multicolumn{2}{|c|}{ Negative binomial analysis } \\
\hline & & $95 \% \mathrm{Cl}$ & p Value & $95 \% \mathrm{Cl}$ & $\mathrm{p}$ Value & $95 \% \mathrm{Cl}$ & p Value \\
\hline $\begin{array}{l}\text { Not intention to treat: patients dropped from } \\
\text { study when they discontinued study }\end{array}$ & 0.79 & 0.63 to 0.98 & 0.03 & 0.54 to 1.14 & 0.21 & 0.55 to 1.01 & 0.06 \\
\hline
\end{tabular}

medications

p Values and 95\% confidence intervals (CI) of adjudicated exacerbation rate ratios are shown. 
patients after they stop study drugs introduces bias since the subsequent exacerbation is not counted and attributed to the study drug in question. In order to be consistent with CONSORT guidelines, ${ }^{47}$ patients who prematurely stop a study medication should not be considered "drop-outs" unless they absolutely refuse permission for the study to continue to follow them. Ideally, these patients should be retained in the study for its duration and any subsequent COPD exacerbations should be attributed to their randomised group.

It should be acknowledged that the intention-to-treat approach to analysis described above is correct, but it is also conservative. In some clinical trials of COPD, proportionately more patients randomised to the placebo limb have exited the study early. Many of these patients subsequently used active open-label therapies for the duration of the study. If such therapies are effective at reducing exacerbations, then an intention-to-treat analysis might reduce the possibility of a difference being found between the placebo group and the active arms in these instances. Since it is impossible to know a priori the direction and magnitude of the effect of patient noncompliance, and because of the potential biases involved in premature exclusion of patients, it is preferable for investigators to report two separate analyses-a true intention-to-treat effectiveness analysis as well as a secondary efficacy analysis that excludes patients when they stop study medications. If the results of both analyses are reported, then the reader can make up his/her mind to decide on the effectiveness of the intervention in question.

Our review of the published literature revealed other methodological issues confounding contemporary COPD clinical trials. None of the trials reported whether or not they determined the independence of individual exacerbation events. The problem is that patients may present to healthcare providers recurrently with symptoms of an acute exacerbation over short periods of time. For instance, a patient may present with symptoms of cough, dyspnoea and sputum to a physician on 1 January and be given an antibiotic, then present again on 7 January for identical symptoms and be given a second antibiotic, then present again on 14 January with the same symptoms and be treated with oral steroids. The question is: are these truly independent events or are these latter two events simply relapses or continuations of the original exacerbation? The negative binomial or Poisson distribution assumes that individual events will be independent of prior events. This assumption can be satisfied if it is clear that the patient had reverted to his/her baseline between events.

The Canadian Optimal Therapy of COPD Trial considered patients to have experienced a new COPD exacerbation if they had been off oral steroids and antibiotics for at least 14 days following their previous exacerbation. ${ }^{11}$ Other options to determine independence could include an assessment of patient symptoms using symptom diaries with a reversion of symptoms to baseline before a new event can be said to occur. ${ }^{48} 49$

None of the 22 trials included in the systematic review employed blinded adjudication of exacerbation events. This is problematic, since trials are thus reliant on the individual investigator to assign an outcome. Problems arise with diagnostic exchange; for example, should a respiratory event be classified as a COPD exacerbation or an upper respiratory tract infection or pneumonia? Adjudication committees can review the assembled clinical and radiographic data to determine if adverse events such as pneumonia had occurred. Adjudicated acute exacerbations of COPD can also be potentially further validated against daily diary card-defined exacerbations. Use of a blinded adjudication committee to review assembled data to ensure that the event met the prestated study definition of a COPD exacerbation can thus help avoid mistakes, inconsistencies and diagnostic exchange.

An analysis of the13 trials that reported the mean number of exacerbations/patient-year revealed that only 4 used analyses which weighed each patient's individual exacerbation rate by their follow-up time. Suissa has shown in a previous "simulated trial" that using unweighted analyses underestimates the rate ratio and thus overestimates the apparent effectiveness of the treatment at preventing exacerbations. ${ }^{9}$ Our analysis of the Canadian Optimal Therapy of COPD Trial used a real-life clinical trial dataset and confirmed Suissa's observations.

Clinicians who treat COPD are aware that there is considerable between-subject variability in COPD exacerbations; two patients with the same degree of lung dysfunction may have markedly different rates of exacerbation. The Poisson regression technique assumes that the variance of the rate of exacerbations is less than and is proportional to the mean, ${ }^{10}$ but in COPD this is unusual. Only 2 of 13 trials published since 2000 correctly accounted for between-subject variation by incorporating an overdispersion parameter into their analysis of the mean number of exacerbations/patient-year. Unless between-subject variability is accounted for by incorporating an overdispersion correction into the Poisson distribution or by using a negative binomial model, then statistical significance may be assumed inappropriately.

The TORCH study was published in early 2007 after completion of our review. This study did use weighted statistical analyses and accounted for between-subject variation when analysing COPD exacerbation rates. ${ }^{50}$ However, COPD exacerbations were not adjudicated in the TORCH trial, and those COPD exacerbations that occurred after patients prematurely discontinued their study medications were not included in the analysis of exacerbation outcomes.

Our systematic review has revealed inconsistencies in how exacerbation rates are reported. Seven of the 22 trials did not report the proportion of patients who experienced at least one exacerbation over the trial period; rather, these studies only reported the mean number of exacerbations per patient-year. Both methods of reporting COPD exacerbations have their merits and disadvantages. The mean number of exacerbations/ patient-year captures patients with multiple exacerbations which may be clinically and economically important. However, measurement of the mean number of exacerbations/patient-year can be heavily influenced by a small minority of patients who experience multiple exacerbation events, and it cannot yield a number-needed-to-treat since this can only be derived from the absolute difference in the proportion of patients who experience at least one exacerbation. ${ }^{51} 52$ Conversely, the proportion of patients who experience at least one exacerbation is not always an ideal measurement since it is heavily influenced by the duration of the trial; for instance, if the study continues for an extended time period, then most/all patients will eventually experience an exacerbation.

We would suggest that trials be designed, and sample sizes calculated, using the mean number of exacerbations per patientyear as the primary outcome. However, it is also important for studies to report the proportion of patients who experienced at least one exacerbation over the trial period as a secondary outcome in order to determine both whether treatment will prevent an individual patient from having an exacerbation and also whether treatment may prevent some patients from having multiple exacerbations. 
An analysis of actual clinical trial data from the Canadian Optimal Therapy of COPD Trial has shown that different methods for counting and analysing COPD exacerbations can result in major differences in the magnitude of the treatment effect. Results can go from statistically insignificant to statistically significant depending on how exacerbation events are counted, analysed and reported.

We would suggest that clinical trials adopt a standard consensus definition for COPD exacerbations and that studies should strive to incorporate parameters in their definition that assure independence of events and use blinded adjudication committees to ensure that suspected COPD exacerbations meet study definitions. Additionally, it would be ideal if trials could use intention-to-treat approaches to discourage premature exclusion of patients from the study analysis after they stop study medications. Correct statistical analysis using weighted mean rates and employing statistical corrections for betweenpatient variability should be obligatory. Use of standardised measures for defining, counting and analysing COPD exacerbations should help ensure comparability of clinical trial results.

Funding: Funded by the Canadian Institutes of Health Research (Grant no. MCT63139) and the Ontario Thoracic Society.

Competing interests: None.

\section{REFERENCES}

1. Anthonisen NR, Manfreda J, Warren CPW, et al. Antibiotic therapy in exacerbations of chronic obstructive pulmonary disease. Ann Intern Med 1987;106:196-204.

2. Seemungal TAR, Donaldson GC, Paul EA, et al. Effect of exacerbation on quality of life in patients with chronic obstructive pulmonary disease. Am J Respir Crit Care Med 1998;157:1418-22.

3. Aaron SD, Vandemheen K, Clinch J, et al. Measurement of short-term changes in dyspnea and disease-specific quality of life following an acute COPD exacerbation. Chest 2002;121:688-96.

4. Miravitlles M, Ferrer M, Pont A, et al. Effect of exacerbations on quality of life in patients with chronic obstructive pulmonary disease: a 2 year follow up study. Thorax 2004;59:387-95.

5. Miravitlles M, Murio C, Guerrero T, et al. Pharmacoeconomic evaluation of acute exacerbations of chronic bronchitis and COPD. Chest 2002;121:1449-55.

6. Pauwels R, Calverley P, Buist AS, et al. COPD exacerbations: the importance of a standard definition. Respir Med 2004;98:99-107.

7. Anthonisen NR, Connet JE, Murray RP. Smoking and lung function of lung health study participants after 11 years. Am J Respir Crit Care Med 2002;166:675-9.

8. Mahler DA, Barbee RA, Gross NJ, et al. Efficacy of salmeterol xinafoate in the treatment of COPD. Chest 1999;115:957-65.

9. Suisa S. Statistical treatment of exacerbations in therapeutic trials of chronic obstructive pulmonary disease. Am J Respir Crit Care Med 2006;173:842-6.

10. Slymen D, Ayala G, Arredondo EM, et al. Analytic perspective: a demonstration of modeling count data with an application to physical activity. Epidemiol Perspect Innnovations 2006;3:1-9.

11. Aaron SD, Vandemheen $\mathrm{K}$, Fergusson D, et al. Tiotropium in combination with placebo, salmeterol, or fluticasone/salmeterol for treatment of chronic obstructive pulmonary disease: a randomized trial. Ann Intern Med 2007;146:545-55.

12. Cazzola $\mathbf{M}$, Noschese $\mathbf{P}$, Centanni $\mathbf{S}$, et al. Salmeterol/fluticasone propionate in a single inhaler device versus theophylline + fluticasone propionate in patients with COPD. Pulm Pharmacol Ther 2004;17:141-5.

13. van Noord JA, Aumann J-L, Janssens E, et al. Comparison of tiotropium once daily, formoterol twice daily and both combined once daily in patients with COPD. Eur Respir J 2005;26:214-22.

14. van Noord JA, Aumann J-L, Janssens E, et al. Effects of tiotropium with and without formoterol on airflow obstruction and resting hyperinflation in patients with COPD. Chest 2006;129:509-17.

15. Verkindre C, Bart F, Aguilaniu B, et al. The effect of tiotropium on hyperinflation and exercise capacity in chronic obstructive pulmonary disease. Respiration 2006; 73:420-7.

16. Casaburi R, Kukafka D, Cooper CB, et al. Improvements in exercise tolerance with the combination of tiotropium and pulmonary rehabilitation in patients with COPD. Chest 2005;127:809-17.

17. Cazzola M, Marco FD, Santus P, et al. The pharmacologic effects of single inhaled doses of formoterol, tiotropium and their combination in patients with COPD. Pulm Pharmacol Ther 2004;17:35-9

18. Aalbers R, Ayres JG, Backer V, et al. Formoterol in patients with chronic obstructive pulmonary disease: a randomized, controlled, 3-month trial. Eur Respir J 2002:19:936-43.
19. Wadbo M, Lofdahl CG, Larsson K, et al. Effects of formoterol and ipratropium bromide in COPD: a 3-month placebo-controlled study. Eur Respir J 2002;20:113846.

20. Make B, Hanania NA, ZuWallack R, et al. The efficacy and safety of inhaled fluticasone propionate/salmeterol and ipratropium/albuterol for the treatment of chronic obstructive pulmonary disease: an eight-week, multicenter, randomized, double-blind, double-dummy, parallel-group study. Clin Ther 2005;27:531-42.

21. Oostenbrink JB, Rutten-Van Mölken MPMH, et al. One-year cost-effectiveness of tiotropium versus ipratropium to treat chronic obstructive pulmonary disease. Eur Respir J 2004;23:241-9.

22. Donohue JD, van Noord JA, Bateman ED, et al. A 6-month, placebo controlled study comparing lung function and health status changes in COPD patients treated with tiotropium or salmeterol. Chest 2002;122:47-55.

23. Vestbo J, Soriano JB, Anderson JA, et al. Gender does not influence the response to the combination of salmeterol and fluticasone propionate in COPD. Respir Med 2004;98:1045-50

24. Di Marco F, Verga M, Santus P, et al. Effect of formoterol, tiotropium, and their combination in patients with acute exacerbation of chronic obstructive pulmonary disease: a pilot study. Respir Med 2006;100:1925-32.

25. van Noord JA, de Munck DRAJ, Bantje ThA, et al. Long-term treatment of chronic obstructive pulmonary disease with salmeterol and the additive effect of ipratropium. Eur Respir J 2000;15:878-85.

26. Zuwallack R.L., Mahler DA, Reilly D, et al.Salmeterol plus theophylline combination therapy in the treatment of COPD. Chest 2001;119:1661-70.

27. Rennard SI, Anderson W, ZuWallack R, et al. Use of a long-acting inhaled $\beta_{2-}$ adrenergic agonist, salmeterol xinafoate, in patients with chronic obstructive pulmonary disease. Am J Respir Crit Care Med 2001:163:1087-92.

28. Chapman K, Arvidsson P, Chuchalin A, et al. The addition of salmeterol 50 mcg bid to anticholinergic treatment in patients with COPD: a randomized, placebo controlled trial. Can Respir J 2002;9:178-85.

29. Rossi A, Kristufek P, Levine MD, et al. Comparison of the efficacy, tolerability, and safety of formoterol dry powder and oral, slow-release theophylline in the treatment of COPD. Chest 2002;121:1058-69.

30. Celli B, Halpin D, Byrne N, et al. Symptoms are an important outcome in chronic obstructive pulmonary disease clinical trials: results of a 3-month comparative study using the Breathlessness, Cough, and Sputum Scale (BCSS). Respir Med 2003;97(Suppl A):S35-43.

31. Stockley RA, Chopra N, Rich L. Addition of salmeterol to existing treatment in patients with COPD: a 12 month study. Thorax 2006;61:122-8.

32. Mahler DA, Wire P, Horstman D, et al. Effectiveness of fluticasone propionate and salmeterol combination delivered via the Diskus device in the treatment of chronic obstructive pulmonary disease. Am J Respir Crit Care Med 2002;166:1084-91.

33. Szafranski W, Cukier A, Ramirez A, et al. Efficacy and safety of budesonide/ formoterol in the management of chronic obstructive pulmonary disease. Eur Respir $J$ 2003:21:74-81.

34. Calverley P, Pauwels R, Vestbo J, et al. Combined salmeterol and fluticasone in the treatment of chronic obstructive pulmonary disease: a randomised controlled trial. Lancet 2003:361:449-56.

35. Calverley PM, Boonsawat W, Cseke Z, et al. Maintenance therapy with budesonide and formoterol in chronic obstructive pulmonary disease. Eur Respir J 2003;22:9129 .

36. Hanania NA, Darken P, Horstman D, et al. The efficacy and safety of fluticasone propionate $(250 \mu \mathrm{g}) /$ salmeterol $(50 \mu \mathrm{g})$ combined in the Diskus Inhaler for the treatment of COPD. Chest 2003;124:834-43.

37. Dal Negro RW, Pomari C, Tognella $S$, et al. Salmeterol and fluticasone $50 \mu \mathrm{g} /$ $250 \mu \mathrm{g}$ bid in combination provides a better long-term control than salmeterol $50 \mu \mathrm{g}$ bid alone and placebo in COPD patients already treated with theophylline. Pulm Pharmacol Ther 2003:16:241-6.

38. Wouters EFM, Postma DS, Fokkens B, et al. Withdrawal of fluticasone propionate from combined salmeterol/fluticasone treatment in patients with COPD causes immediate and sustained disease deterioration: a randomized controlled trial. Thorax 2005;60:480-7.

39. Kardos P, Wencker M, Glaab T, et al. Impact of salmeterol/fluticasone propionate versus salmeterol on exacerbations in severe chronic obstructive pulmonary disease. Am J Respir Crit Care Med 2007:175:144-9.

40. Casaburi R, Mahler DA, Jones $\mathrm{P}$, et al. A long-term evaluation of once-daily inhaled tiotropium in chronic obstructive pulmonary disease. Eur Respir J 2002;19:217-24.

41. Vincken W, van Noord JA, Greefhorst APM, et al. Improved health outcomes in patients with COPD during 1 yr's treatment with tiotropium. Eur Respir $J$ 2002;19:209-16.

42. Brusasco V, Hodder R, Miravitlles M, et al. Health outcomes following treatment for six months with once daily tiotropium compared with twice daily salmeterol in patients with COPD. Thorax 2003;58:399-404.

43. Niewoehner DE, Rice KL, Cote CG, et al. Prevention of exacerbations of chronic obstructive pulmonary disease with tiotropium, a once-daily inhaled anticholinergic bronchodilator. A randomized trial. Ann Intern Med 2005;143:317-26.

44. Briggs DD Jr, Covelli H, Lapidus R, et al. Improved daytime spirometric efficacy of tiotropium compared with salmeterol in patients with COPD. Pulm Pharmacol Ther 2005; 18:397-404.

45. Dusser $\mathbf{D}$, Bravo ML, lacono $\mathrm{P}$, on behalf of the MISTRAL study group. The effect of tiotropium on exacerbations and airflow in patients with COPD. Eur Respir $J$ 2006;27:547-55. 
46. Beeh KM, Beier J, Buhl R, et al. Efficacy of tiotropium bromide (Spiriva) in patients with chronic obstructive pulmonary disease (COPD) of varying severity. Pneumologie 2006;60:341-6.

47. Moher D, Schulz KF, Altman DG. The CONSORT statement: revised

recommendations for improving the quality of reports of parallel-group randomized trials. Ann Intern Med 2001;134:657-62.

48. Spencer S, Jones PW, Globe Study Group. Time course of recovery of health status following an infective exacerbation of chronic bronchitis. Thorax 2003;58:589-93.
49. Seemungal TAR, Donaldson GC, Bhowmik A, et al. Time course and recovery of exacerbations in patients with chronic obstructive pulmonary disease. Am J Respir Crit Care Med 2000;161:1608-13.

50. Calverley PM, Anderson JA, Celli B, et al. Salmeterol and fluticasone propionate and survival in chronic obstructive pulmonary disease. N Engl J Med 2007;356:775-89.

51. Altman DG. Confidence intervals for the number needed to treat. BMJ 1998;317:1309-12

52. Cook RJ, Sackett DL. The number needed to treat: a clinically useful measure of treatment effect. BMJ 1995;310:452-4.

\section{Pulmonary puzzle}

\section{A hint of calcium}

\section{CLINICAL PRESENTATION}

A 76-year-old male who was a previous smoker presented with symptoms suggestive of recurrent lower respiratory tract infections. There was no associated anorexia, weight loss or breathlessness. During one of these episodes he had haemoptysis which prompted further investigations with a CT scan of the chest as well as a flexible bronchoscopy. The CT scan showed some thickening of the tracheobronchial mucosa and specks of calcification in the trachea as well as the major bronchi. The posterior wall of the trachea was spared (fig 1A, B). The bronchoscopic appearances were rather unusual. Extensive "nodularity" was seen more or less throughout the whole trachea with relative sparing of the posterior aspect. Similar changes were seen also in the major upper airways (fig 1C). These "nodules" had a rather gritty feeling on contact with the bronchoscope. Purulent secretions were also visualised. These $\mathrm{CT}$ and bronchoscopy findings are characteristic of the underlying pathology which was confirmed on biopsy (fig 1D).

\section{QUESTION}

What is the diagnosis?

See page 153 for answer

This case is submitted by:

\section{S Faruqi, R Regester, M Thirumaran, S Williams}

Department of Respiratory Medicine, Pinderfields General Hospital, Wakefield, West Yorkshire, UK

Correspondence to: Dr S Faruqi, Department of Respiratory Medicine, Pinderfields General Hospital, Aberford Road, Wakefield, West Yorkshire WF1 4DG, UK; sfaruqi@doctors.net.uk;

Competing interests: None.

Thorax 2008:63:128. doi:10.1136/thx.2007.088237
Figure $1(A, B)$ Thickening of the tracheobronchial mucosa with areas of calcification. The posterior wall of the trachea is spared. (C) Bronchoscopic appearance at the carina. There are mucosal "nodules" seen and purulent secretions. (D) Haematoxyllin and eosin photomicrograph of the bronchial biopsy which is diagnostic. The diagnostic features are annotated with arrows.
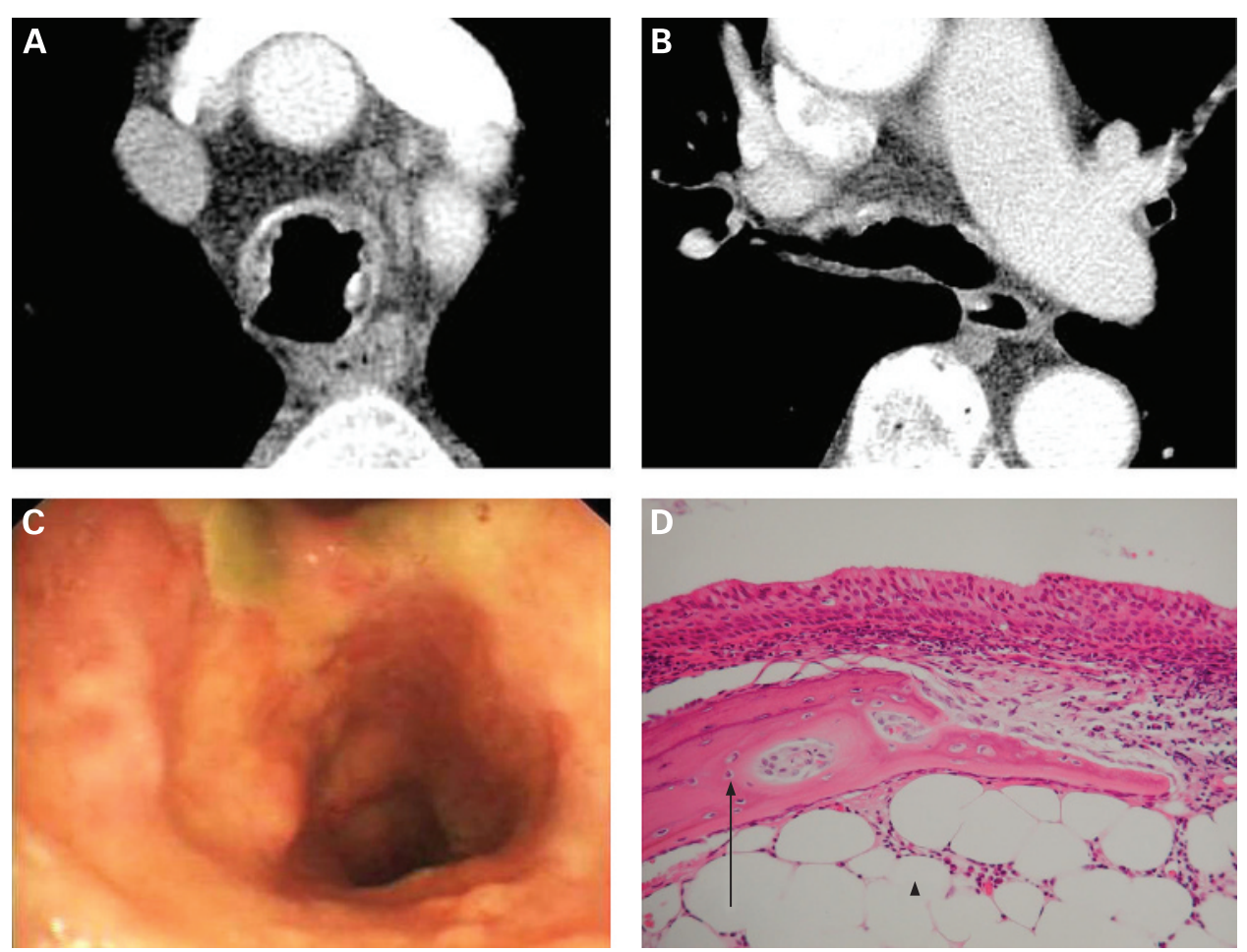